\title{
PENGARUH UKURAN BANK, STRUKTUR MODAL, SUKU BUNGA DAN \\ LOAN TO DEPOSIT RATIO TERHADAP PROFITABILITAS PADA PERUSAHAAN PERBANKAN YANG TERDAFTAR DI BURSA EFEK INDONESIA
}

\section{THE INFLUENCE OF BANK SIZE,CAPITAL STRUCTURE,INTEREST RATIO AND LOAN TO DEPOSIT RATIO ON PROFITABILITY OF BANKING COMPANIES REGISTERED IN INDONESIA STOCK EXCHANGE}

\author{
Evonella Nainggolan ${ }^{1}$, Jessy Safitri Sitorus ${ }^{2}$ \\ Universitas Prima Indonesia, Medan ${ }^{1,2}$ \\ Evonellanainggolan@gmail.com ${ }^{1}$
}

\begin{abstract}
Banking in carrying out its operational activities is always required to achieve high profitability. This study aims to examine the effect of Bank Size, Capital Structure, Interest Rates and Loan to Deposit Ratio on the Profitability of Banking Companies Listed on the Indonesia Stock Exchange 2016-2019 Period. The approach that processes the research data is a quantitative approach. The population in this study were 43 companies with 25 samples of banking companies listed on the Indonesia Stock Exchange for the 2016-2019 period. The data analysis method used is multiple linear regression test. The results of this study are that Bank Size has an effect on Profitability, Capital Structure has an effect on Profitability, Interest Rates have no effect on Profitability, and Loan to Deposit Ratio has no effect on Profitability in Banking Companies Listed on the Indonesia Stock Exchange Period 2016-2019. Simultaneously, Bank Size, Capital Structure, Interest Rate and Loan to Deposit Ratio affect the Profitability of Banking Companies Listed on the Indonesia Stock Exchange 2016-2019 Period. Keywords: Bank Size, Capital Structure, Interest Rates, Loan to Deposit Ratio and Profitability.
\end{abstract}

Keywords : Bank Size, Capital Structure, Interest Rates, Loan to Deposit Ratio and Profitability.

\begin{abstract}
ABSTRAK
Perbankan dalam menjalankan kegiatan operasionalnya selalu dituntut pencapaian profitabilitas yang tinggi. Penelitian ini bertujuan untuk menguji pengaruh Ukuran Bank, Struktur Modal, Suku Bunga dan Loan to Deposit Ratio terhadap Profitabilitas pada Perusahaan Perbankan yang Terdaftar di Bursa Efek Indonesia Periode 2016-2019. Pendekatan yang mengolah data penelitian ini adalah pendekatan kuantitatif. Populasi dalam penelitian ini adalah 43 Perusahaan dengan 25 sampel perusahaan Perbankan yang Terdaftar di Bursa Efek Indonesia Periode 2016-2019. Metode analisis data yang digunakan adalah uji regresi linear berganda. Adapun hasil penelitian ini adalah Ukuran Bank berpengaruh Terhadap Profitabilitas, Struktur Modal berpengaruh Terhadap Profitabilitas, Suku Bunga tidak berpengaruh Terhadap Profitabilitas, dan Loan to Deposit Ratio tidak berpengaruh Terhadap Profitabilitas pada Perusahaan Perbankan yang Terdaftar di Bursa Efek Indonesia Periode 2016-2019. Secara simultan Ukuran
\end{abstract}


Bank, Struktur Modal, Suku Bunga dan Loan to Deposit Ratio berpengaruh Terhadap Profitabilitas

Kata Kunci : Ukuran Bank, Struktur Modal, Suku Bunga, Loan to Deposit Ratio dan Profitabilitas.

\section{PENDAHULUAN}

Dunia perbankan berperan vital dalam perekonomian indonesia. Perbankan merupakan tempat menyediakan pembiayaan, penyimpanan serta peminjaman jadi pada akhirnya akan memakmurkan kehidupan masyarakat. Perbankan dalam operasionalisasinya diharuskan mencapai profitabilitas yang besar. tingkat profitabilitas perbankan sering naik turun. Fluktuatif laba perbankan ini dipengaruhi oleh ukuran bank, struktur modal bank, suku bunga BI, dan LDR.

Bank yang besar tentunya mempunyai profitabilitas yang besar sementara bank yang kecil tentunya mempunyai profitabitas yang kecil. Mayoritas investor dalam melakukan investasi pasti akan memilih bank yang besar (Peling \& Sedana 2018)

Bank yang menarik perhatian masyarakat bukan dilihat dari ukuran bank nya saja tetapi juga dipengaruhi struktur modal yang dimiliki bank. Perbankan memiliki struktur modal sendiri tinggi tentu menghasilkan profitabilitas tinggi dari pada bank memiliki struktur modal pinjaman.

Bank juga memberikan suku bunga kepada nasabahnya dan biasanya suku bunga bank di tentukan berdasarkan BI rate. Suku bunga BI ini tiap waktu akan mengalami perubahan sehingga laba yang di hasilkan bank juga naik turun. Suku bunga BI tinggi maka laba di hasilkan tinggi (Wibowo 2013).

Tingginya laba yang dihasilkan bank akan dipergunakan dana tersebut untuk disalurkan kembali ke masyarakat dalam bentuk LDR. LDR tinggi maka keuntungan yang di dapatkan perbankan akan tinggi begitu juga sebaliknya LDR rendah maka laba di peroleh bank menjadi rendah. Total aktiva dimiliki bank rakyat Indonesia Agro Niaga tbk ditahun 2019 naik mendorong terjadinya penurunan laba bersih di Tahun 2019 seharusnya total aktiva dapat menaikkan laba bersih. Total hutang dimiliki bank capital Indonesia tbk di tahun 2018 naik mendorong terjadinya kenaikan laba bersih seharusya total hutang naik maka laba bersih turun. Dana pihak ke tiga di miliki bank Bukopin tbk di tahun 2019 naik mendorong penurunan laba bersih di tahun 2019 seharusnya dana pihak ke tiga naik maka laba bersih naik. Suku bunga bank mestika dharma tbk di tahun 2017 turun mendorong kenaikan laba bersih seharusnya suku bunga turun maka laba bersih turun.

Permatasari (2020) pada
dasarnya perusahaan besar yang menyimpan total aktiva tinggi sanggup membikin profit tinggi pula. Kian tinggi asset pembianyaan yang disalurkan akan kian tinggi yang menantinya bisa memberikan profit bagi bank. Jika profit naik profitabilitas bank juga akan naik.

Lontoh (2019), penurun DER berpengaruh pada peningkatan ROA. Hal ini sesuai dengan teori bahwa penggunaan hutang yang tinggi mengharuskan perusahaan membanyar bunga yang tinggi sehingga mengurangi laba yang akhirnya menurunkan nilai return on asset (ROA).

Menuru Wira (2015), jika suku bunga naik maka perusahaan tidak akan mampu mengembalikan kredit, 
sehingga mau tidak mau harga barangnya akan naik. Apabila harga barang nya naik maka perusahaan tidak akan mendapatkan keuntungan.

\section{METODE PENELITIAN}

Penelitian ini di buat di bursa efek Indonesia. Pemeriksaan ini dibuat untuk memeriksa benarkah ukuran bank, stuktur modal, suku bunga dan loan to deposit ration terhadap profitabilitas pada perusahaan perbankan yang terdaftar di bursa efek Indonesia periode 2016-2019. Pendekatan kuantitatif di gunakan dalam mengelolah data. Penelitian ini berjenis kuantitatif yang sifatnya hubungan sebab akibat populasi yang dipakai di pemeriksaan ini yaitu 43 perusahaan perbankan yang tercatan di BEI periode 2016-2019. Tekni pengambilan sampal yaitu teknik purposive sampling.

Dipemeriksaan ini metode analisis data yang dipakai ialah teknik analisis statistic. Saat data belum di periksa maka, kepentingan data analisis tersebut lebih dulu di buat uji asumsi klasik sebelum pembuatan uji hipotesis. Analisis data dalam mengolah data menggunakan SPSS ( statistical product And Service Sol Sulation). Bentuk analisis data ini menggunakan analisis regresi berganda agar dapat di ketahui pengaruh variable bebas ( indevenden) dan terikat (devenden digunkan rumus analisis regresi linear berganda sebagai berikut.

$\mathrm{Y}=\mathrm{a}+\mathrm{b}_{1} \mathrm{X}_{1}+\mathrm{b}_{2} \mathrm{X}_{2}+\mathrm{b}_{3} \mathrm{X}_{3}+\mathrm{b}_{4} \mathrm{X}_{4}+\mathrm{e}$

Dengan:

$\mathrm{Y}=$ Profitabilitas

a $\quad=$ Konstanta

$\mathrm{b}_{1}, \mathrm{~b}_{2}, \mathrm{~b}_{3}, \mathrm{~b}_{4}=$ Keadaan Regresi

$\mathrm{X}_{1} \quad=$ Variabel Ukuran Bank

$\mathrm{X}_{2} \quad=$ Variabel Struktur Modal

$\mathrm{X}_{3} \quad=$ Variabel Suku Bunga

$$
\begin{array}{ll}
\mathrm{X}_{4} & =\text { Variable Loan To Deposit } \\
\text { Ratio } & \\
\mathrm{e} & =\text { Estimasi kesalahan }(0,05)
\end{array}
$$

\section{HASIL DAN PEMBAHASAN}

Uji signifikan secara farsial (T-Test)

Pengunaan uji $t$ tujuan nya

adalah menguji apakah variabel bebasnya mempengaruhi variabel

\begin{tabular}{|c|c|c|c|c|c|c|}
\hline \multirow{2}{*}{\multicolumn{2}{|c|}{ Model }} & \multicolumn{2}{|c|}{ Unstandardized Coefficents } & \multirow{2}{*}{$\begin{array}{l}\text { Standardized } \\
\text { Coefficents } \\
\text { Beta }\end{array}$} & \multirow[b]{2}{*}{ t } & \multirow[b]{2}{*}{ Sig. } \\
\hline & & B & Std Error & & & \\
\hline 1 & (Constant) & .8818 & 1.315 & & -6.708 & .000 \\
\hline & $\overline{U K}$ & 389 & .043 & .653 & 9.072 & .000 \\
\hline & DER & .233 & .029 & .577 & .8 .107 & .000 \\
\hline & SBI & .001 & .000 & .114 & 1.645 & .103 \\
\hline & $\overline{\mathrm{LDR}}$ & .007 & .004 & .125 & -1.723 & .088 \\
\hline
\end{tabular}
terikat.

Tabel 1 Hasil Pengujian Statistic Uji t

a. Dependent Variable: $R O A$

1. Ukuran bank $t_{\text {hitung }}=9,072$, sig $=$ $0,000 \quad t_{\text {tabel }} \quad(100-4=96)=1,984$, $\mathrm{t}_{\text {hitung }}>\mathrm{t}_{\text {tabel }}, 9,072>1,984 \mathrm{H}_{\mathrm{o}}$ ditolak, $\mathrm{H}_{\mathrm{a}}$ diterima ditunjukkan Ukuran Bank mempengaruhi profitabilitas.

2. Struktur modal $t_{\text {hitung }}=-8,107$, sig $=$ $0,000, t_{\text {tabel }} 1,984-t_{\text {hitung }}<-t_{\text {tabel }}-8,107<$ $-1,984 \quad \mathrm{H}_{\mathrm{o}}$ ditolak, $\mathrm{H}_{\mathrm{a}}$ diterima ditunjukkan struktur modal mempengaruhi profitabilitas.

3. Suku buga $t_{\text {hitung }}=1,645$, sig $=0,103$, $\mathrm{t}_{\text {tabel }} 1,984 \mathrm{t}_{\text {hitung }}<\mathrm{t}_{\text {tabel, }} 1,645<1,984$ $\mathrm{H}_{\mathrm{o}}$ diterima, $\mathrm{H}_{\mathrm{a}}$ ditolak ditunjukkan suku bunga tidak mempengaruhi profitabilitas.

4. Loan to deposit Ratio $t_{\text {hitung }}=-1,723$ f> -1,984 $\mathrm{H}_{\mathrm{o}}$ Diterima, $\mathrm{H}_{\mathrm{a}}$ Ditolak ditunjukkan LDR tidak mempengaruhi profitabilitas.

Tabel 2 Hasil Pengujian Secara Simultan Uji F

\begin{tabular}{llrr|r|r|r} 
Model & & Sum of Squares & df & Mean Square & F & Sig. \\
\hline 1 & 52.771 & 4 & 13.193 & 30.562 & $.000^{6}$ \\
\hline & Regression & 41.010 & 95 & .432 & & \\
\cline { 2 - 7 } & Residual & 93.781 & 99 & & & \\
\hline Total & 99 & & & \\
\hline
\end{tabular}

a. Dependentit Variable: ROA

b. Predidcors: (Constant), LDR, DER, SBI, UK 
$\mathrm{F}_{\text {hitung }}=30,562$, sig $=0,000$ dan $F_{\text {tabel }} \quad(100-5=95) \quad 2,47 . \quad$ F hitung $>F_{\text {tabel }}$ yaitu $30,562>2,47$ terlihat $\mathrm{H}_{\mathrm{o}}$ ditolak, $\mathrm{H}_{\mathrm{a}}$ diterima ditunjkukkan ukuran Bank, struktur Modal, suku Bunga dan LDR mempengaruhi Profitabilitas.

\section{Pengarus Ukuran Bank terhadap Profitabilitas}

Hasil penelitian ini adalah ukuran Bank mempengaruhi profitabilitas. Hasil penelitiannya sejalan dengan pernyataan dari Yuniari (2019), besarnya aktiva yang sebuah Bank miliki, dalam mengelola bank tersebut akan makin berhati-hati, karena tanggung jawab Bank yang merupakan sebuah lembaga yang memerlukan kepercayaan public akan besar. Selain hal tersebut, tingginya aktiva bank, akan membuat bank lebih mempunyai kesempatan dalam menambah keuntungan ataupun laba.

\section{Pengaruh Struktur Modal terhadap Profitabilitas}

Hasil dari penelitiannya adalh struktur modal mempengaruhi profitabilitas. Hasil penelitiannya sejalan dengan pernyataan dari Lontoh (2019), penurunan DER berpengaruh pada peningkatan ROA, hal ini sesuai dengan teori bahwa penggunaan hutang yang tinggi sehingga mengurangi lana yang akhirnya menurunkan nilai ROA.

\section{Pengaruh suku bunga terhadap profitabilitas}

Hasil penelitian ini yaitu suku bunga tidak mempengaruhi profitabilitas. Hasil penelitiannya sejalan dengan pernytaan dari Ayerza (2018), suku bunga ialah harga dari pemakaian hutang ataupun umum dipersepsikan dengan sewa atas pemakain hutang dalam jangka panjang waktu tertentu, ataupun harga dari peminjaman uang untuk mempergunakan daya belinya dan umumnya dituliskan dengan persentase. Jika suku bunganya besar, otomatis seorang akan lebih senang melakukan penyimpanan uang di bank sesab masyarakat pasti mengiginkan pengambilan yang memberikan keuntungan.

\section{Pengaruh Loan to Deposit Ratio terhadap Profitabilitas}

Hasil penelitiannya adalah LDR tidak mempengaruhi profitabilitas. Hasil penelitiannya tidak sejalan sengan peryataan dari Ambarawati \& Nyoman (2018), makin besar ratio LDR, maka makin besar juga profitabilitasn suatu bank.

\section{PENUTUP}

\section{Kesimpulan}

Berdasaarkan pada hasil penelitian, bisa disimpulkan yaitu:

1. Ukuran Bank, Struktur Modal, mempengaruhi profitabilitas pada perusahaan perbankan yang tercatat di BEI tahun 2016-2019

2. Suku bunga, LDR tidak mempengaruhi profitabilitas di perusahaan perbankan yang tercatat di BEI tahun 2016-2019.

3. Ukuran Bank, Struktur Modal, suku bunga dan LDR mempengaruhi profitabilitas di perusahaan perbankan yang tercatat di BEI tahun 2016-2019

\section{Saran}

Mengacu dari kesimpulan yang diberikan tersebut, maka saran yang di berikan yaitu :

1. Sebaiknya pihak manajemen meningkatkan total aktiva, Loan to deposit Ratio agar laba dapat meningkat sedangkan struktur modal perusahaan lebih baik menggunakan laba di tahan dimiliki 
perusahaan guna mengurangi utang dan mengikuti suku bunga BI rate.

2. Bagi peneliti berikutnya untuk memperbanyak variabel bebasnya yang memberikan pengarus terhdap profitabilitas dan memperpanjang masa pengamatan.

3. Bagi universitas prima Indonesia, alangkah baiknya hasil penelitiannya ini bisa dipergunakan oleh mahasiswa dan mahasiswa yang lainya.

DAFTAR PUSTAKA

Ambarawati, G., A.,D \& Nyoman A. (2018). Pengaruh Capital Adequacy Ratio, Non Performing Loan, Loan To Deposit Ratio Terhadap Return On Aseet. EJurnal Manajemen Unud, 7(5): 2410-2441.

Ayerza. (2018). Analisis Pengaruh Tingkat Suku Bunga Dan Inflasi Terhadap Profitabilitas Perbankan Yang Terdaftar Di Bursa Efek Indonesia Periode 2010 - 2016. Manajemen Keuangan. Institut Bisnis dan Informatika Kwik Kian Gie.

Lontoh, R., S. (2019). Pengaruh Struktur Modal, Kepemilikan Institusional Dan Ukuran Perusahaan Terhadap Profitabilitas Pada Industri Keuangan Non Bank Yang Terdaftar Di Bursa Efek Indonesia. Jurnal EMBA. 7(3):4154- 4163.

Peling, A \& Sedana. (2018). Pengaruh LDR, NPL, Dan BOPO Terhadap Profitabilitas Pada PT. BPD Bali Periode Tahun 2009-2016. EJurnal Manajemen Unud, 7(6): 2999-3026.

Permatasari, D, F. (2020). Analisis Determinant Profitabilitas Pada Industri Perbankan Syariah Periode 2011-2018 Pendekatan
Auto Regresive Distributed Lag (ARDL). Jurnal Ekonomi Syariah Teori dan Terapan, 7(6): 1102-1117.

Wibowo, S. (2013). Analisis Pengaruh Suku Bunga, Inflasi, CAR, BOPO, NPF Terhadap Profitabilitas Bank Syariah. Diponegoro Journal Of Management 2(2): 2337-379.

Wira, D. (2015). Analisis Fundamental Saham. Edisi Kedua. Jakarta : Penerbit Exceed

Yuniari, B. (2019). Pengaruh Likuiditas, Efisiensi, Dan Ukuran Bank Terhadap Profitabilitas. EJurnal Manajemen, 8(6):35023530 . 